\title{
Polyploidy and Induced Gametangial Formation in British Isolates of Phytophthora infestans
}

\author{
By E. SANSOME \\ 6 Roydon Road, Diss, Norfolk IP22 $3 L N$ \\ (Received 15 October 1976; revised 9 December 1976) \\ SUMMARY
}

Gametangial (sex organ) formation in cultures of a British isolate of Phytophthora infestans, mating type $\mathbf{A}^{1}$, was induced by simultaneous inoculation with both $\mathrm{A}^{1}$ and $\mathrm{A}^{2}$ isolates of $P$. palmivora. Inoculation with the $\mathrm{A}^{2}$ mating type only was ineffective. Three isolates of $P$. infestans were examined: two were polyploid, of which one was probably tetraploid; the third had both diploid and polyploid nuclei.

Phytophthora infestans also produced gametangia when inoculated simultaneously with both $\mathrm{A}^{1}$ and $\mathrm{A}^{2}$ types of $P$. cambivora and $P$. cinnamomi. The ecological significance of these findings is discussed.

\section{INTRODUCTION}

Since Phytophthora infestans is heterothallic and only the $\mathrm{A}^{1}$ mating type is present in temperate regions, it has been widely assumed that it does not reproduce sexually in these regions. However, it has long been known that the mating type reaction in Phytophthora is non-specific, $\mathbf{A}^{1}$ types of one species often reacting with $\mathrm{A}^{2}$ types of a different species (Stamps, 1953; Haasis \& Nelson, 1963; Ribeiro, Erwin \& Zentmyer, 1975). In such reactions where both parents produce both oogonia and antheridia, there may be reciprocal hybrid gametangial combinations and also a certain proportion of selfed gametangial combinations. The latter might be expected to produce some viable oospores even if the hybrid combinations fail to do so.

Some preliminary matings of British isolates of $P$. infestans with $\mathrm{A}^{2}$ mating types of other species were largely ineffective. It was thought that these isolates might be able to react with $\mathrm{A}^{2}$ types stimulated to undergo sexual reproduction by another compatible $\mathrm{A}^{\mathbf{1}}$ type. To interpret mating reactions in a triple inoculation it is essential to choose compatible $\mathrm{A}^{1}$ and $\mathrm{A}^{2}$ types with easily recognizable gametangia. Such 'marked' gametangia are provided by the ' $L$ ' and ' $S$ ' chromosome types of the $P$. palmivora complex (Sansome, Brasier \& Griffin, 1975). Recent observations on isolates obtained from cocoa in West Africa, attributed to $P$. palmivora, have indicated the presence of two types which have very distinctive chromosome complements (Sansome et al., 1975): the ' $S$ ' (small chromosome) type, having a basic complement of about nine small chromosomes; and the ' $L$ ' (large chromosome) type, having a basic complement of five much larger chromosomes. The ' $L$ ' type has very distinctive nuclei at metaphase since, besides having larger and fewer chromosomes than is usual in Phytophthora, the chromosomes form a characteristic narrow spindle. Four or possibly six chromosomes are associated in a ring or chain at metaphase. Because of the distinctive appearance of the ' $L$ ' type nuclei it was possible to investigate the 
Table I. Origin of Phytophthora species

\begin{tabular}{|c|c|c|c|}
\hline Organism & Isolate no. & Mating type & Origin \\
\hline $\begin{array}{l}\text { Phytophthora } \\
\text { palmivora ' } L \text { ' }\end{array}$ & PI32 & $\mathbf{A}^{\mathbf{1}}$ & Nigeria; Sansome et al., I975 \\
\hline P. palmivora ' $\mathrm{L}$ ' & PI 84 & $A^{2}$ & Cameroun; Sansome et al., 1975 \\
\hline P. palmivora ' $\mathrm{S}$ ' & PI3I & $\mathbf{A}^{2}$ & Nigeria; Sansome et al., 1975 \\
\hline$P$. infestans & B25 & $\mathbf{A}^{1}$ & UK; Shattock \& Shaw, I975 \\
\hline P. infestans & PYF2 & $\mathbf{A}^{\mathbf{1}}$ & $\begin{array}{l}\text { UK; Dr R. Shattock, University } \\
\text { College of North Wales }\end{array}$ \\
\hline P. infestans & Treb A & $\mathbf{A}^{\mathbf{1}}$ & UK; Dr R. Shattock \\
\hline$P$. infestans & $63 B$ & $\mathbf{A}^{1}$ & Mexico; Sansome \& Brasier, 1973 \\
\hline P. infestans & 445 & $\mathbf{A}^{2}$ & Mexico; Sansome \& Brasier, 1973 \\
\hline P. cambivora & IMI77374 & $\mathbf{A}^{2}$ & France \\
\hline P. capsici & 504 & $\mathbf{A}^{1}$ & Mexico; Timmer et al., 1970 \\
\hline P. capsici & $505 \mathrm{~s}$ & $\mathbf{A}^{2}$ & Mexico; Timmer et al., 1970 \\
\hline P. cinnamomi & IMII977I 5 & $A^{2}-$ & UK \\
\hline P. cryptogea & IMI45I68 & $\mathbf{A}^{\mathbf{1}}$ & New Zealand \\
\hline P. cryptogea & IMII 32646 & $\mathbf{A}^{2}$ & Egypt \\
\hline P. drechsleri & 6500 & $\mathbf{A}^{\mathbf{1}}$ & $\begin{array}{l}\text { Mexico; Galindo \& Zentmyer, } \\
1967\end{array}$ \\
\hline P. drechsleri & 6503 & $\mathbf{A}^{2}$ & $\begin{array}{l}\text { Mexico; Galindo \& Zentmyer, } \\
\text { I967 }\end{array}$ \\
\hline P. erythroseptica & - & - & $\begin{array}{l}\text { UK; Professor J. Webster, } \\
\text { University of Exeter }\end{array}$ \\
\hline $\begin{array}{l}P \text {. nicotianae var. } \\
\text { parasitica }\end{array}$ & IMI35087 & & UK \\
\hline
\end{tabular}

effect of ' $L$ ' $\mathrm{A}^{1} \times{ }^{\text {' }} \mathrm{L}$ ' $\mathrm{A}^{2} P$. palmivora cultures on $P$. infestans. The first $P$. infestans culture so tested was found to be polyploid and therefore distinctive; thus it was possible to test the reaction of this isolate with other species.

\section{METHODS}

The isolates used in these experiments are described in Table $\mathrm{I}$.

The mating reaction tests were carried out on carrot agar (Brasier, 1975a). A large inoculum (about $\mathrm{I}$ to $\mathrm{I} \cdot 5 \mathrm{~cm}$ diam.) of an actively growing culture of $P$. infestans on rye agar (Caten \& Jinks, 1968) was placed on the carrot agar together with an $A^{2}$ type of another species. For triple inoculations, inocula of $P$. infestans and of the $\mathrm{A}^{1}$ and $\mathrm{A}^{2}$ types of the other species were placed on the agar approximately equidistant from each other.

The mated cultures were examined microscopically for sex organs when the colonies met. After sexual reproduction was observed in the intraspecific combination, particular attention was given to the $P$. infestans inoculum and its immediate surroundings. When sex organs were observed in or near the $P$. infestans inoculum (usually 2 or more days after vigorous mating in the intraspecific region), they were fixed and examined cytologically.

Samples of agar containing oogonia were sliced and treated with iced water for $\mathrm{I}$ to $2 \mathrm{~h}$. After removal of excess water, the samples were fixed for 30 to $45 \mathrm{~min}$ in ethanol/glacial acetic acid $(3: I, v / v)$, transferred to ethanol/diethyl ether $(I: I, v / v)$ for 2 days to remove fatty substances, then placed in ethanol/acetic acid $(3: 1, v / v)$ or ethanol for not less than I $\mathrm{h}$ and thoroughly washed in water. The material was stained or stored in $70 \%(\mathrm{v} / \mathrm{v})$ ethanol. Aceto-orcein squash preparations were made as described previously (Sansome, $1976)$, after treatment for $10 \mathrm{~min}$ in $\mathrm{I} \%(\mathrm{w} / \mathrm{v})$ citric acid. 


\section{RESULTS AND DISCUSSION}

\section{Induction of sex organ formation in P. infestans by mated cultures of other Phytophthora species}

No oogonia were produced when $\mathrm{B} 25$ ( $P$. infestans $\mathrm{A}^{1}$ ) was paired with PI84 (P. palmivora ' $L$ ' $A^{2}$ ) and only once in many tests were a few oogonia produced when $B 25$ was paired with PI3I ( $P$. palmivora ' $S$ ' $\left.A^{2}\right)$. However, when strain $B 25$ was inoculated with PI $84 \times$ PI32 (P. palmivora ' $\mathrm{L}$ ' $\mathrm{A}^{2} \times{ }^{\prime} \mathrm{L}$ ' $\mathrm{A}^{1}$ ) or with PI3I $\times$ PI 32 ( $P$. palmivora 'S' $\left.\mathrm{A}^{2} \times{ }^{\prime} \mathrm{L}^{\prime} \mathrm{A}^{1}\right)$, oogonia were freely produced in the region of the $P$. infestans inoculum a few days after they had appeared at the junction of the $P$. palmivora $\mathrm{A}^{1} \times \mathrm{A}^{2}$ colonies - usually about 6 days after inoculation. These oogonia, which could be identified cytologically because their nuclei were at late prophase or metaphase, were found to be predominantly of a new type, distinct from either the ' $L$ ' or ' $S$ ' $P$. palmivora types. They had larger chromosomes than the ' $S$ ' type and more chromosomes than either the ' $S$ ' or ' $L$ ' types. Presumably they were $P$. infestans oogonia. Multivalents in the form of rings or chains were often present. In most cases when the oogonial nuclei were at metaphase, the antheridial nuclei had already divided and could not therefore be identified. However, Fig. I shows metaphase in a $\boldsymbol{P}$. palmivora ' $L$ ' oogonium and Fig. 2 shows metaphase in a $P$. infestans oogonium and in the attached ' $L$ ' type antheridium. The number of chromosomes in the nuclei of the $P$. infestans oogonium is approximately twice that previously observed in a cross between two isolates of $P$. infestans from Mexico, (445) $\mathrm{A}^{2} \times(63 \mathrm{~B}) \mathrm{A}^{1}$ (Sansome \& Brasier, 1973). In the latter cross, metaphases were observed with an association of up to six chromosomes and about six pairs of chromosomes. Figure 3 shows metaphase in an oogonium from the $445 \times 63 \mathrm{~B}$ cross; comparison with Fig. 2 indicates that the oogonial nuclei from a British isolate of $P$. infestans have approximately twice as many chromosomes.

\section{Polyploidy in British isolates of $P$. infestans}

The discovery of polyploidy in $P$. infestans B25 raises the question as to how widespread this phenomenon is in temperate regions. Since strain B25 had been maintained in culture for some time, two new strains, PYF2 and Treb A, were tested with mated P. palmivora cultures. Strain PYF2 produced polyploid oogonia (Fig. 2) in the combination PYF $2 \times P$. palmivora ' $L$ ' $A^{1} \times P$. palmivora ' $L$ ' $A^{2}$. Strain Treb A produced polyploid oogonia, diploid oogonia and some oogonia with both diploid and polyploid nuclei and was therefore a diploid-polyploid heterokaryon. These findings suggest that $P$. infestans may exist in nature in the tetraploid condition and this may indeed be the prevalent condition in temperate isolates. An extensive examination of the ploidy of such isolates is urgently needed. It may be that the tetraploid is better adapted to cooler conditions and that it has resulted from the selection of the auto-tetraploid nuclei which must occasionally arise in regions of rapid division. Alternatively, the tetraploid could be an allopolyploid which arose from the doubling of a hybrid between $P$. infestans and some other species. The fact that many pathogenic races of $P$. infestans have been discovered (Malcolmson, 1969) may be due to polyploidy in $P$. infestans.

\section{Reactions of $P$. infestans $\mathrm{B} 25$ with other species}

Since $P$. infestans 825 could be distinguished cytologically by its high chromosome number, it was possible to identify it in combinations involving species other than $\boldsymbol{P}$. palmivora. Tests were made with a number of species including some found in temperate zones. 


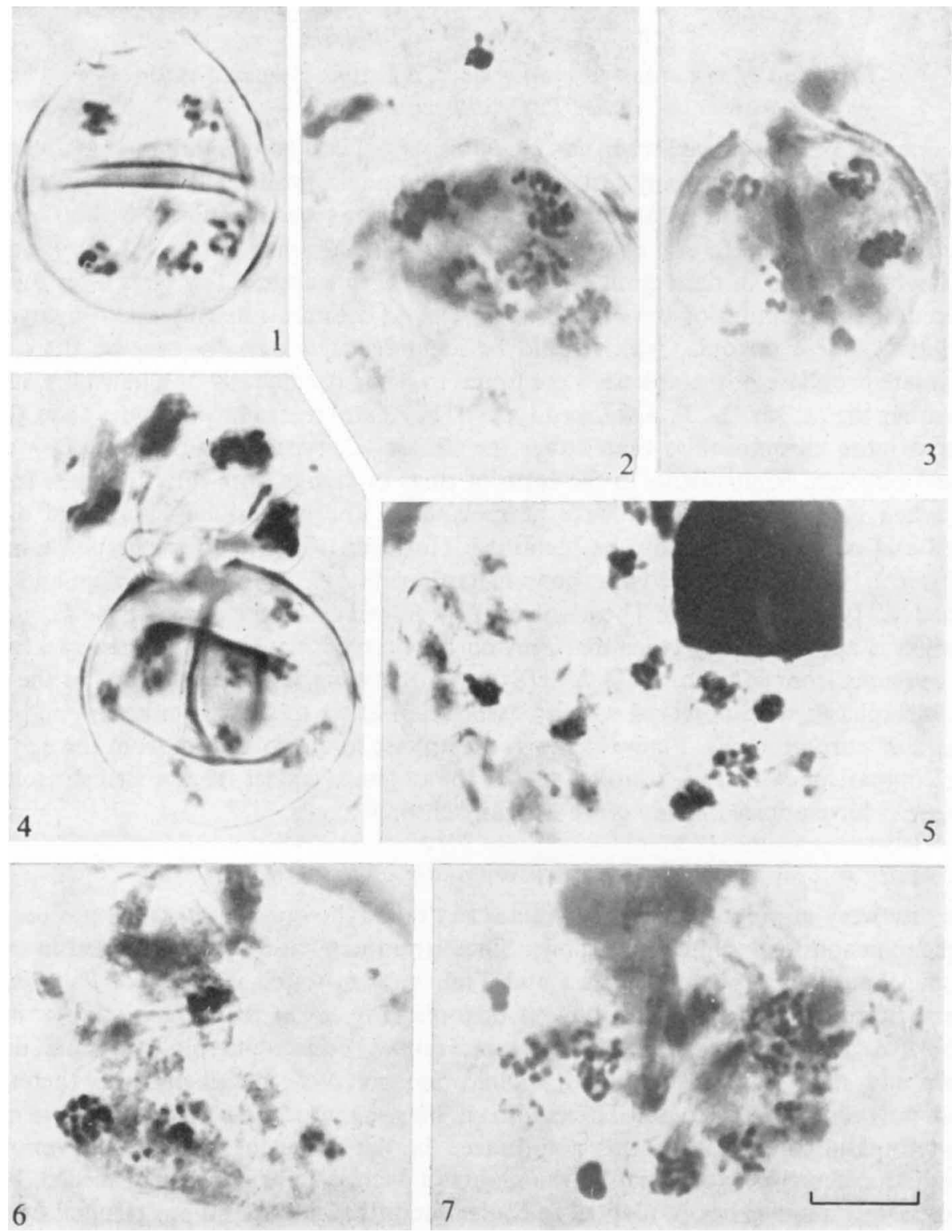

Bar marker represents $\mathrm{I} \mu \mathrm{m}$.

Fig. I. Metaphase $I$ in a $P$. palmivora ' $L$ ' oogonium (from Treb A $\times$ PI $32 \times$ P 184 ).

Fig. 2. Metaphase $I$ in a $P$. infestans oogonium (British) (from PYF2 $\times$ PI $32 \times$ PI 84 ).

Fig. 3. Metaphase $I$ in a $P$. infestans oogonium (Mexican) (from 63B $\times 445$ ).

Fig. 4. Metaphase I in a $P$. nicotianae var. parasitica oogonium (from $P$. nicotianae var. parasitica $\times$ B25).

Fig. 5. Metaphases from a squashed out $P$. infestans oogonium (from $P$. nicotianae var. parasitica $\times$ B25).

Fig. 6. Metaphase $\mathrm{I}$ in part of a $P$. cambivora oogonium (from $P$. cambivora $\mathrm{A}^{2} \times \mathrm{B} 25$ ).

Fig. 7. Metaphase I in part of a $P$. infestans oogonium (from $P$. cambivora $A^{2} \times B 25$ ). 
The homothallic $P$. erythroseptica, tested because it was found on potato (Pitt, 1975), was ineffective in inducing sexual reproduction in $P$. infestans B25. However, a homothallic strain of $P$. nicotianae var. parasitica, which had $2 n=\sim$ I8 chromosomes, induced the production of oogonia and antheridia in $P$. infestans B25. Figure 4 shows metaphase in a $P$. nicotianae var. parasitica oogonium and in the attached $P$. infestans antheridium. The nuclei in the antheridium are much larger than those of the oogonium. The oogonia produced in this combination are sparse and, possibly because of this, the B25 oogonia have particularly thick, heavily staining walls which obscure the nuclei. Figure 5 shows the squashed out contents and part of the wall of such an oogonium. The nuclei are readily distinguishable from those of $P$. nicotianae var. parasitica seen in the oogonium in Fig. 4 since they have about twice as many chromosomes. Phytophthora nicotianae var. parasitica has heterothallic as well as homothallic strains and therefore the factors required for sexual reproduction in this species may be different from those of a truly homothallic species such as $P$. erythroseptica. Phytophthora cambivora $\mathrm{A}^{2}$, which had $2 n=\sim 18$ chromosomes, was tested because it is widely distributed (Brasier, 1975b) and because it has characteristic projections on the oogonial wall which could possibly serve as an additional distinguishing feature. It reacted slowly with $P$. infestans B25, gametangial formation starting in the region of the B25 inoculum after about II days. Samples were fixed between II and I6 days after inoculation. The production of oogonia was sparse but a number of oogonia at late prophase and metaphase were observed. Figure 6 shows part of a $P$. cambivora oogonium and Fig. 7, part of a squashed $P$. infestans oogonium, both at metaphase. The $P$. cambivora oogonia were usually larger than those of $P$. infestans and the nuclei were sparser and less readily stained. The oogonial wall projections characteristic of $P$. cambivora were not always visible in the early stages. This character may be variable in expression or it may be influenced by the type of attached antheridium. In later stages, the $P$. cambivora oogonia had less deeply staining walls with projections and a narrower layer of periplasm than the $P$. infestans oogonia. Mated cultures of $P$. drechsleri $(6500 \times 6503)$ and of $P$. capsici $(504 \times$ 505 s) induced gametangial production in $P$. infestans $\mathrm{B25}$ although $P$. drechsleri $\mathrm{A}^{2}$ alone did not. The interspecific combinations, P. cinnamomi $\mathrm{A}^{2} \times P$. cryptogea $\mathrm{A}^{1}$ and $P$. cambivora $\mathrm{A}^{2} \times P$. cryptogea $\mathrm{A}^{1}$, were also effective. It seems that the reaction of the British $P$. infestans with an $\mathrm{A}^{2}$ mating type of another species may be initiated or enhanced by the presence of another $\mathrm{A}^{1}$ type although mated cultures of $P$. cryptogea $\mathrm{A}^{1} \times \mathrm{A}^{2}$ were ineffective.

\section{Ecological significance}

The fact that British isolates of $P$. infestans may undergo sexual reproduction in the presence of $\mathrm{A}^{2}$ mating types of such species as $P$. cambivora and $P$. cinnamomi, which are of widespread occurrence in the $\mathrm{A}^{2}$ form (Brasier, 1975b; Zentmyer, 1976), may have important ecological implications. Selfing is readily induced in $\mathrm{A}^{2}$ mating types of the two latter species by Trichoderma viride. The sexual reaction of $P$. infestans with a $P$. cambivora or $P$. cinnamomi $\mathrm{A}^{2}$ type might be greatly increased in the presence of Trichoderma viride or other micro-organisms with a similar effect. Since the oogonial and attached antheridial nuclei were often at different stages, it was rarely possible to distinguish between hybrid and selfed gametangial combinations. However, a number of hybrid gametangial combinations were observed (Figs 2 and 4 ). No selfed combination was identified and it seems probable that hybrids are more frequent than selfed gametangial combinations. It is, therefore, likely that most oospores resulting from the reaction of $\boldsymbol{P}$. infestans with another species would be hybrid and possibly non-viable. However, a certain proportion of selfed oospores would be expected to occur and some of these might survive in nature. Boccas \& Zentmyer 
(1976) found that a cross between $P$. cinnamomi and $P$. parasitica resulted in the formation of oospores but only $5 \%$ were well-formed and only $5 \%$ of these germinated to give single oospore progeny. Some of the progeny resembled the parental types and were assumed to be the result of selfing. Others were assumed to be the result of segregation in selfed oospores. In the case of tetraploids, such as the $P$. infestans isolates studied here, occasional unfertilized oospores might develop giving rise to diploid cultures. If these are somewhat unbalanced, somatic doubling would give a diploid-tetraploid heterokaryon such as occurs in the Treb A isolate.

If viable oospores are sometimes formed by $\boldsymbol{P}$. infestans in nature by reaction with other Phytophthora species, they would enable the organism to survive unfavourable conditions. They would also lead to a greater degree of segregation than ordinary somatic reproduction.

Thanks are due to Drs C. M. Brasier, R. C. Shattock, D. J. Stamps, J. Webster and G. A. Zentmyer for supplying cultures, to Dr F. W. Sansome for taking the photographs and to The Royal Society for a grant without which this work would not have been possible.

\section{REFERENCES}

BOCCas, B. \& ZENTMYER, G. A. (1976). Genetical studies with interspecific crosses between Phytophthora cinnamomi and Phytophthora parasitica. Phytopathology 66, 477-484.

Brasier, C. M. (1975a). Stimulation of sex organ formation in Phytophthora by antagonistic species of Trichoderma. I. The effect in vitro. New Phytologist 74, 183-194.

Brasier, C. M. (1975b). Stimulation of sex organ formation in Phytophthora by antagonistic species of Trichoderma. II. Ecological implications. New Phytologist 74, 195-198.

Caten, C. E. \& Jinks, J. L. (1968). Spontaneous variability of single isolates of Phytophthora infestans. I. Cultural variation. Canadian Journal of Botany 46, 329-348.

Galindo, J. A. \& ZeNTMYer, G. A. (1967). Genetical and cytological studies of Phytophthora strains pathogenic to pepper. Phytopathology 57, $1300-1304$.

HaAsis, F. A. \& NeISON, R. R. (1963). Studies on the biological relationship of species of Phytophthora as measured by oospore formation in intra- and inter-specific crosses. Plant Disease Reporter 47, 705-709.

Malcoumson, J. F. (1969). Races of Phytophthora infestans occurring in Great Britain. Transactions of the British Mycological Society 53, 417-423.

Prrt, D. (1975). Changes in the sub-cellular location of catalase and $o$-diphenol oxidase during infection of potato tubers by Phytophthora erythroseptica. Transactions of the British Mycological Society 65, 9I-100.

RIBERo, O. K., ERWIN, D. C. \& ZeNTMYer, G. A. (I975). An improved synthetic medium for oospore production and germination of several Phytophthora species. Mycologia 67, 1012-1019.

Sansome, E. (1976). Gametangial meiosis in Phytophthora capsici. Canadian Journal of Botany 54, 15351545 .

Sansome, E. \& Brasier, C. M. (1973). Diploidy and chromosomal structural hybridity in Phytophthora infestans. Nature, London 241, 344-345.

Sansome, E., Brasier, C. M. \& Griffin, M. J. (1975). Chromosome size differences in Phytophthora palmivora, a pathogen of cocoa. Nature, London 255, 704-705.

Shatrock, R. C. \& Shaw, D. S. (1975). Mutants of Phytophthora infestans resistant to, and dependent upon, antibiotics. Transactions of the British Mycological Society 64, 29-4I.

Stamps, D. J. (1953). Oospore production in paired cultures of Phytophthora species. Transactions of the British Mycological Society 36, 255-259.

Tamer, L. W., Castro, J., Erwin, D. C., Belser, W. L. \& Zentmyer, G. A. (1970). Genetic evidence for zygotic meiosis in Phytophthora capsici. American Journal of Botany 57, $1211-1218$.

ZENTMYer, G. A. (1976). Distribution of the $\mathbf{A}^{1}$ mating type of Phytophthora cinnamomi. Phytopathology 66, $701-703$. 